\title{
Keynote: Just Enough Requirements Management for Web Engineering
}

\author{
Al Davis \\ College of Business \\ University of Colorado at Colorado Springs \\ Colorado Springs, CO 80933-7150 USA \\ adavis@uccs.edu
}

\section{Brief Bio}

Al Davis is professor of information systems at the University of Colorado at Colorado Springs. He was a member of the board of directors of Requisite, Inc., acquired by Rational Software Corporation in February 1997, and subsequently acquired by IBM in 2003. He has consulted for many corporations over the past twenty-seven years, including Boeing, Cigna Insurance, Federal Express, FrontRange Solutions, Fujitsu, General Electric, Great Plains Software, IBM, Loral, MCI, Mitsubishi Electric, NEC, NTT, Rational Software, Rockwell, Schlumberger, Sharp, Software Productivity Consortium, Storage Tek, and Sumitomo. Previously, he was

- Chairman and CEO of Omni-Vista, Inc., a software company in Colorado Springs;

- Vice President of Engineering Services at BTG, Inc., a Virginia-based company that went public in 1995, and was acquired by Titan in 2001;

- a Director of R\&D at GTE Communication Systems in Phoenix, Arizona. GTE was acquired by Verizon in 1999;

- Director of the Software Technology Center at GTE Laboratories in Waltham, Massachusetts.

He has held academic positions at George Mason University, University of Tennessee, and University of Illinois at Champaign-Urbana. He was Editor-inChief of IEEE Software from 1994 to 1998. He is an editor for the Journal of Systems and Software (1987-present) and was an editor for Communications of the ACM (1981-1991). He is the author of

- Software Requirements: Objects, Functions and States (Prentice Hall, 1st edition 1990; 2nd edition 1993);

- the best-selling 201 Principles of Software Development (McGraw Hill, 1995);

- Great Software Debates (Wiley and IEEE CS Press, 2004), and

- Just Enough Requirements Management (Dorset House, 2005).

Dr. Davis has published $100+$ articles in journals, conferences and trade press, and lectured 500+ times in over 20 countries. Much of his current research 
centers around discovering "just enough" ways of performing requirements engineering, specifically "the largely unexplored middle ground between the requirements purists and the requirements cowboys." [Tom DeMarco] He maintains the most extensive bibliography on the web for requirements-related subjects (http://web.uccs.edu/adavis/reqbib.htm). He is the founder of the IEEE International Conferences of Requirements Engineering, and served as general chair of its first conference in 1994. He has been a fellow of the IEEE since 1994, and earned his Ph.D. in Computer Science from the University of Illinois in 1975. Find out more about Al Davis at http://web.uccs.edu/adavis.

\section{Talk Abstract}

When building web applications, strong temptation exists to "just build it." After all, the tools available today for web engineering are just so easy to use. The operational environment is so tolerant of implementation problems. And the expectations of the user community allow for constant evolution. On the other hand, almost every type of application, including those that are highly financialcritical and life-critical, is migrating to the web. This trend works against the attitude of "just build it." So, the answer cannot be "forget about requirements; we'll figure them out later." And the answer cannot be "write a formal requirements specification for all parties to approve prior to system implementation." Requirements management exists to reduce risk, but it also needs to be made simpler, not more complex. And in today's competitive world we need to find ways to accelerate system development dramatically; modern requirements management must thus reduce, not extend, the effort.

The Capability Maturity Model (CMM) movement has tended to cause companies to over-methodize, while the agile programming movement has tended to cause companies to under-methodize. The result is that requirements are either over-analyzed and over-specified, or are totally ignored. This common-sense talk addresses the "right" level at which requirements should be addressed, with emphasis on recognizing that the "right" level is different for every project.

The talk will cover all three major areas of requirements management: elicitation, triage, and specification. Each will be described, its goals will be made clear, common practices will be described, and recommendations for doing it in a "just enough" manner for web engineering will be explored. The talk will also discuss the factors that would cause you to want to alter the "just enough" prescription for your own needs. 